\title{
Eco Resort Wear Sizing System Targeting Jeju's Medical Tourists
}

\author{
Sookhee Kwon, Jiun Hong \\ Department Clothing \& Textiles, The National University of Jeju, Jeju, 690-756
}

\begin{abstract}
Objective: The purpose of this research was to aid creating an effective sizing system for the vacation wear intended for Jeju's medical tourists, specifically females from the major countries including the USA, Japan, and Korea. Background: Medical tourism makes the gains of every year $40,000,000,000$ dollar, every year $30 \%$ it is increasing. Thus the Jeju-do is propelling medical tourism. The body size each country is different. Consequently must set the body size standard for the women. Method: (1) It observed the body size of the Korean women of 2004 years and 2010 years. (2) It analyzed the body size of the women of the USA, China, Japan and Korea. (3) It set the sizing system of the women of the USA(ASTM), China (GB), Japan(JIS) and Korea(KS). Results: Korean adult females' height in 2010 has increased from 2004. The Waist Back Length, Waist Front Length, Arm Length etc has also increased along with the Height. The upper body has become slimmer at the same time; the Chest Circumference, Bust Circumference, and Underbust Circumference have decreased. The lower body on the other hand has become bigger: the Waist Circumference and Hip Circumference have increased. The BMI has decreased by 0.4 from 2004 - the Height has increased while Weight has decreased. The Chest Circumference and Under Bust Circumference of Korean women across all age groups have increased at a proportional rate to other parts of body; however, the rate of increase in Chest Circumference was far greater. American females(Caucasians) had the greatest ratio of waist to bust (Waist Circumference/Chest Circumference), smallest ratio of Neck Base Circumference to Bust Circumference (neck/bust). Korean females had smallest ratio of Waist Circumference to Underbust Circumference(waist/bust). As for the drop of Chest Circumference and Waist Circumference, American females had the highest and Koreans had the lowest. As for the drop of Hip Circumference and Chest Circumference, Japanese had the highest and Americans had the lowest, but Japanese women at the same time showed the A line body shapes. As for difference of Chest Circumference and Underbust Circumference, American females had the biggest(13.73) followed by Korean(11.1), Japanese(10.9) and Chinese(10.5). Conclusion: The women of the USA, China, Japan and Korea body size is different. Especially the value of the Bust Circumference - the Underbust Circumference is different. Thus, it set the sizing system(Table 8).
\end{abstract}

Keywords: Sizing system, Drop value, Eco resort wear, Medical tourism

\section{Introduction}

관광산업 중 의료관광은 자국에서 받기 어려운 양질의 의
료서비스를 해외여행 과정에서 저렴한 가격에 신속하고 편 리하게 받을 수 있게 함으로써 세계적으로 새로운 의료관광 이동을 창출하고 있다. Martin Springs(2005)에 따르면, 의료관광은 세계적으로 이미 연평균 400 억 달러의 수익을

Corresponding Author: Jiun Hong. Department Clothing \& Textiles, The National University of Jeju, Jeju, 690-756.

Mobile: +82-10-6304-0107, E-mail: texhong@naver.com

Copyright@2012 by Ergonomics Society of Korea(pISSN:1229-1684 eISSN:2093-8462). All right reserved.

(c) This is an open-access article distributed under the terms of the Creative Commons Attribution Non-Commercial License(http://creativecommons.org/licenses/by-nc/3.0/), which permits unrestricted non-commercial use, distribution, and reproduction in any medium, provided the original work is properly cited. http://www.esk.or.kr 
내고 있고, 매년 $30 \%$ 씩 급성장하고 있다. 이러한 국제적 환 경변화 속에서 세계 각국은 의료서비스 시장에서 자국의 경 쟁력을 확보하기 위한 전략을 국가 차원에서 수립하여 지원 하고 있는 데, 이에 정부도 제주특별자치도 출범과 함께 제 주도를 명실상부한 국제자유도시로 발돋움시키기 위해 의 료와 관광산업을 $4+1$ 핵심산업으로 육성에 매진하고 있다 (Ko, 2008). 이를 위해 제주국제자유개발도시센터는 2012 년을 개장을 목표로 중국, 대만, 홍콩 등 중화권과 일본인 부 유층이 주요 타깃으로 '제주헬스케어시티 조성사업'을 실시 하고 있다(Lim, 2006). 산업간 융복합화의 세계화 추세에서 의료관광산업은 또 다른 국내 의류산업에 활력을 불어넣을 수 있는 좋은 기회가 될 것이다. 그 이유는 최근 한류 붐을 타고 중국, 일본을 비롯하여 미국, 러시아, 몽골, 말레이시아, 베트남 등 아시아 여러 나라에서 한국으로의 성형관광을 선 택하고 있으며, 재미동포, 일본인, 중국인의 한국치료 선호분 야는 피부과를 포함한 미용성형을 선택하고 있다고 하였다 (Byun, 2009). 특히, 제주에서 경험하고 싶은 건강관리 및 웰빙분야는 종합건강진단, 스파, 마사지, 해수치료, 피부미용 및 다이어트에 관심이 높은 것으로 조사되었다(Ko, 2008). 따라서, 의료와 휴양을 위한 목적으로 방문하는 관광객을 상 대로 피부질환 개선이라는 기능성 휴양복을 개발하여 판매 가 이루어진다면, 의료관광의 질적 향상과 수입창출에 많은 기여를 할 것으로 판단된다.

제주도는 예전부터 감물염색 상품이 현재까지도 이어져 관광상품으로서 자리매김하고 있다. 최근에는 천연염색의 피 부질환 개선효과와 기능성이 검증된 바가 있어(Han et al., Lee et al., 2008), 의료와 관광을 위해 방문하는 관광객을 대상으로 제주도의 천연염색인 갈천을 활용한 휴양복을 개 발하여 판매한다면, 홍보나 판매에 도움이 될 것으로 기대된 다. 그러나 휴양복 개발을 위해서는 외국인의 체형과 더불 어 사이즈체계 확립과 패턴 개발 등의 해결할 과제가 있다. Sung (2006); Lee et al. (2009)은 인간의 체형은 성별, 연 령, 인종, 시대 및 지역별로 현저한 차이가 나타나는 점에서 이웃나라인 일본과 중국만 보더라도 한국 여성과 체형이 다 르다고 하였다. 현재까지 국내에서 국외를 대상으로 사이즈 체계를 다룬 연구(Shim, 2007; Shim and Kown, 2003; Wee and Sohn, 2006)는 주로 중국인을 대상으로 한 연구 가 있으며 기술표준원의 보고서에는 한국, 미국, 유럽, 일본, 중국 등 치수표를 제시하고 있지만, 치수간격이나 치수체계 는 제각각이다. Lee(2005)는 대부분 젖가슴둘레를 이용하 여 설계방법은 젖가슴둘레가 같은 경우 몸통의 크기를 반영 할 수 없는 문제점을 지적하였다. 이러한 측면에서 주요 관 광국의 사이즈체계 분석과 설정을 위해서는 국내의 성인 여 성의 신체치수 변화에 대해서도 세부적으로 관찰할 필요가 있다. 이에 연구는 사이즈코리아의 데이터를 활용하여 국내
성인 여성의 신체치수의 변화를 고찰하고, 연령별 젖가슴둘 레와 젖가슴아래둘레차(이하 가슴드롭)의 분포율 분석과 함 께 통계 분석을 통해 가슴드롭를 고려한 사이즈체계의 필요 성을 입증하고, 아울러, 미국, 중국, 일본, 한국의 주요 관광 국의 성인 여성의 사이즈체계를 함께 분석하여, 가슴드롭을 고려한 사이즈체계와 세부치수표를 함께 제시하는 데 있다. 이번 연구에서는 국내 성인 여성의 패턴제작과 관련된 신체 치수 항목 변화를 고찰해보고, 주 방문국가인 한국 $(\mathrm{KS})$, 미 국(ASTM), 중국(GB), 일본(JIS) 4 개국 사이즈체계 규격을 분석하여 가슴드롭을 고려한 사이즈체계를 제시하는 데 있 다. 국내 성인 여성의 연령별 젖가슴둘레와 가슴드롭 분포, 가슴드롭에 대한 통계분석과 세부치수표는 후속연구로 제시 하고자 한다. 이렇게 제시한 사이즈체계표를 도내업체가 활 용하는 것이 본 연구의 목적이다.

\section{Method}

본 연구의 사이즈체계 설정을 위한 데이터는 국내 20 60세의 성인 여성의 신체치수 분석은 사이즈코리아의 2004 년과 2010년의 직접측정 자료를 사용하였고, 사이즈체계 설 정은 한국, 미국, 중국, 일본의 4 개국의 치수체계인 $\mathrm{KS}(\mathrm{KS}$ 0050), ASTM(ASTM D 5585-95), GB(GB/T 1335.2), JIS (JIS L 4005)의 자료를 사용하였다. 자료 수집 및 분석 기간은 2010년 12월부터 2011년 3월까지 실시하였다.

본 연구는 국내 성인 여성의 신체치수 변화를 분석하여 변 화가 있다는 것은 사이즈체계 설정하는 데 있어 뒷받침이 된 다. 따라서, 첫째 한국 성인 여성의 신체치수 변화를 분석 하기 위해 20 59세를 대상의 사이즈코리아의 2004년과 2010년의 직접측정 자료를 이용하여 신체치수 평균을 분석 하였으며, 신체치수 항목은 패턴 설계 시 필요한 6 개의 길이 항목, 7 개의 둘레항목, 키, 몸무게, $\mathrm{BMI}$ 항목 등 총 16 개의 항목이 사용되었다(Table 1). 그리고, 25 29세의 백분위에 대한 가슴둘레, 젖가슴둘레, 겨드랑앞벽사이길이, 겨드랑뒤벽 사이길이, 목밑둘레와 젖가슴아래둘레 6항목 대해 2010년 직접측정 자료를 분석하였다. 둘째 한국, 미국, 중국, 일본의 성인 여성의 신체치수 비교 분석을 위해 16 개의 신체치수 항목(Table 1)과 신체비율을 분석하기 위해 '젖가슴둘레허리둘레', '엉덩이둘레-허리둘레', '엉덩이둘레-젖가슴둘레', '젖가슴둘레-젖가슴아래둘레'의 드롭 4 개와 젖가슴둘레와 젖 가슴아래둘레에 대한 허리둘레, 엉덩이둘레, 목밑둘레, 손목 둘레, 겨드랑앞벽사이길이, 겨드랑뒤벽사이길이의 지수치를 분석하였다(Table 2). 한국, 미국, 중국, 일본 성인 여성 사이즈체계 설정을 위해, $\mathrm{KS}(\mathrm{KS}$ 0050), ASTM(ASTM D 
5585-95), GB(GB/T 1335.2), JIS(JIS L 4005)의 사이 즈체계를 분석하여, 젖가슴둘레와 젖가슴아래둘레를 반영한 사이즈체계를 설정하였다.

Table 1. Item of body sizes

\begin{tabular}{l|l|c}
\hline Item & Interscye, Front & Mark \\
\hline \multirow{5}{*}{ Length } & Interscye, Back & L1 \\
& Bust point-bust point & L2 \\
& Biacromion length & L3 \\
& Waist back length & L4 \\
& Arm length & L5 \\
& Neck base circumference & L6 \\
\hline \multirow{5}{*}{ Circumference } & Chest circumference & C2 \\
& Bust circumference & C3 \\
& Underbust circumference & C4 \\
& Waist circumference & C5 \\
& Hip circumference & C6 \\
& Wrist circumference & C7 \\
\hline
\end{tabular}

Stature

Weight $(\mathrm{kg})$

BMI

Table 2. Item of drop values and body indexes

\begin{tabular}{l|c}
\hline \multicolumn{1}{c|}{ Item } & $\begin{array}{c}\text { Calculation } \\
\text { formula }\end{array}$ \\
\hline Bust circumference - Waist circumference & $\mathrm{C} 3-\mathrm{C} 5$ \\
\hline Hip circumference - Waist circumference & $\mathrm{C} 6-\mathrm{C} 5$ \\
\hline Hip circumference - Bust circumference & $\mathrm{C} 6-\mathrm{C} 3$ \\
\hline Bust circumference - Underbust circumference & $\mathrm{C} 3-\mathrm{C} 4$ \\
\hline Waist circumference / Bust circumference & $\mathrm{C} 5 / \mathrm{C} 3$ \\
\hline Hip circumference / Bust circumference & $\mathrm{C} 6 / \mathrm{C} 3$ \\
\hline Neck base circumference / Chest circumference & $\mathrm{C} 1 / \mathrm{C} 3$ \\
\hline Wrist circumference / Bust circumference & $\mathrm{C} 7 / \mathrm{C} 3$ \\
\hline Interscye, Front / Bust circumference & $\mathrm{L} 1 / \mathrm{C} 3$ \\
\hline Interscye, Back / Bust circumference & $\mathrm{L} 2 / \mathrm{C} 3$ \\
\hline Waist circumference / Underbust circumference & $\mathrm{C} 5 / \mathrm{C} 4$ \\
\hline Hip circumference / Underbust circumference & $\mathrm{C} 6 / \mathrm{C} 4$ \\
\hline Neck base circumference / & $\mathrm{C} 1 / \mathrm{C} 4$ \\
\hline Underbust circumference & $\mathrm{C} 7 / \mathrm{C} 4$ \\
\hline Wrist circumference / Underbust circumference & $\mathrm{L} 1 / \mathrm{C} 4$ \\
\hline Interscye, Front / Underbust circumference & $\mathrm{L} 2 / \mathrm{C} 4$ \\
\hline Interscye, Back / Underbust circumference
\end{tabular}

\section{Results}

\subsection{Analysis of compare 2004 with 2010 of body size of Korean women}

2004년과 2010년 20세에서 59세까지 한국 여성의 신체 치수 변화를 보면(Table 3) 가슴둘레, 젖가슴둘레, 젖가슴아 래둘레는 감소한 반면, 허리둘레와 엉덩이둘레는 증가하였으 며, 등길이, 앞중심길이, 목옆허리선길이, 젖꼭지사이수평길 이, 팔길이는 증가한 반면, 겨드랑앞벽사이길이와 겨드랑뒤 벽사이길이, 목옆젖꼭지길이는 감소한 것으로 나타났다. 또 한, 키는 $1575.4 \mathrm{~mm}$ 에서 $1586 \mathrm{~mm}$ 로 $11 \mathrm{~mm}$ 증가하였으며, 몸무게는 $56.4 \mathrm{~kg}$ 에서 $55.6 \mathrm{~kg}$ 로 $0.8 \mathrm{~kg}$ 감소하였으며, 신체 충실지수(BMI)는 키의 증가와 몸무게 감소로 인해 22.5에 서 22.1로 0.4 감소하였다. 2004년에 비해 2010년의 한국 여성의 신체는 키가 커짐에 따라 등길이, 앞중심길이, 팔길 이 등이 같이 증가하였으며, 상체 몸통은 날씬해져 가슴둘레, 젖가슴둘레, 젖가슴아래둘레가 감소하였고, 반면, 하체는 좀

Table 3. Body size comparison of 2004 and 2010 Korean women(mm)

\begin{tabular}{l|r|r|r|c}
\hline \multirow{2}{*}{ Year } & \multicolumn{2}{|c|}{2004} & \multicolumn{2}{c}{2010} \\
\cline { 2 - 5 } & Mean & S.D. & Mean & S.D. \\
\hline Chest circumference & 857.7 & 53.2 & 857 & 58.1 \\
\hline Bust circumference & 868.9 & 67.8 & 866 & 75.5 \\
\hline Underbust circumference & 758.1 & 52.1 & 755 & 63 \\
\hline Waist circumference & 739.2 & 72.3 & 745 & 83.9 \\
\hline Hip circumference & 920.0 & 50.8 & 925 & 50.7 \\
\hline Waist back length & 384.7 & 22.7 & 394 & 21.8 \\
\hline Waist front length & 327.9 & 21.3 & 344 & 19.8 \\
\hline Interscye, Front & 324.7 & 18.6 & 318 & 20.5 \\
\hline Interscye, Back & 369.2 & 22.8 & 364 & 24.6 \\
\hline Biacromion length & 396.7 & 22.8 & 389 & 22.7 \\
\hline Neck point to breast & 405.8 & 23.0 & 421 & 23.2 \\
point to waistline & 264.4 & 22.7 & 262 & 24.1 \\
\hline Neck shoulder point & 177.3 & 18.7 & 179 & 16.6 \\
\hline to breast point & 528.0 & 22.8 & 538 & 24.6 \\
\hline Bust point-bust point & 305.3 & 13.9 & 313 & 17.2 \\
\hline Arm length & 150.6 & 8.2 & 150 & 8.7 \\
\hline Upperarm length & 374.2 & 21.4 & 387 & 22.7 \\
\hline Wrist circumference & 1575.4 & 49.9 & 1586 & 56.2 \\
\hline Neck base circumference & 56.4 & 7.5 & 55.6 & 7.72 \\
\hline Stature & & & & \\
\hline Weight & & & & \\
\hline & & & & \\
\hline
\end{tabular}


Table 4. The body size change of the Korean women at each percentiles(mm)

\begin{tabular}{|c|c|c|c|c|c|c|c|c|c|c|c|}
\hline \multirow{2}{*}{ Item } & \multirow{2}{*}{ Mean } & \multirow{2}{*}{ S.D } & \multicolumn{9}{|c|}{ Percentile } \\
\hline & & & 1th & 5 th & 10th & 25 th & 50th & 75 th & 90th & 95 th & 99th \\
\hline Chest circumference & 831 & 48.9 & 737 & 763 & 772 & 795 & 827 & 860 & 901 & 920 & 968 \\
\hline Bust circumference & 834 & 58.9 & 718 & 751 & 764 & 793 & 832 & 866 & 916 & 945 & 1004 \\
\hline Under circumference & 726 & 47.5 & 642 & 658 & 672 & 691 & 719 & 752 & 786 & 824 & 850 \\
\hline Interscye, Front & 314 & 18.3 & 275 & 283 & 292 & 302 & 314 & 326 & 338 & 345 & 360 \\
\hline Interscye, Back & 358 & 22.6 & 310 & 321 & 330 & 343 & 357 & 372 & 385 & 398 & 412 \\
\hline Neck base circumference & 380 & 18.6 & 345 & 352 & 355 & 367 & 380 & 390 & 405 & 415 & 424 \\
\hline
\end{tabular}

더 커져 허리둘레와 엉덩이둘레가 증가하였다. 키가 커짐과 동시에 몸무게는 감소하여 2004년에 비해 2010년 한국 여 성의 신체는 좀 더 날씬해진 것을 알 수 있다. 이와 같은 결 과는 현재의 사이즈체계를 다시 재설정의 필요성을 제시하 고 있다.

\subsection{Analysis of body size increasing rate by age, percentiles}

패턴 제도 시 필요한 치수는 패턴종류 별로 다르나, 특히 젖가슴둘레만으로 다른 부위를 산출하는 패턴이 가지는 문 제점은 비슷한 젖가슴둘레에서 젖가슴아래둘레와 같은 몸통 은 작고 젖가슴이 큰 체형과 몸통은 큰 데 젖가슴이 작은 체 형들에게 패턴반영이 되지 않기 때문에 맞음새에 문제가 발 생한다. 따라서 젖가슴둘레 외에 몸통크기를 반영할 수 있는 신체치수, 즉 젖가슴아래둘레와 같은 신체치수 적용이 필요 하다. 젖가슴아래둘레의 패턴제작이나 사이즈체계에 적용 시 고려해야 할 점은 젖가슴아래둘레가 커짐에 따라 다른 부위 의 치수도 증가해야 사이즈체계나 패턴에 적용시킬 수 있다. 따라서 본 연구에서는 연령별, 각 백분위수 별로 젖가슴둘레 와 젖가슴아래둘레의 변화와 패턴 제도 시 산출되는 겨드랑 앞벽사이길이와 겨드랑뒤벽사이길이, 목너비와 목깊이와 관 계가 있는 목밑둘레의 변화를 살펴보았다. 20대 후반을 백분 위수로 분석한 결과(Table 4) 젖가슴아래둘레와 젖가슴둘레, 가슴둘레, 겨드랑앞벽사이길이, 겨드랑뒤벽사이길이, 목밑둘 레는 젖가슴둘레의 증가율이 다른 신체치수에 비해 훨씬 크 게 증가하고 있어 젖가슴둘레만으로 만든 패턴의 맞음새에 문제가 있음을 설명하고 있다.

\subsection{Body size comparison of women of Korea, USA, China and Japan}

사이즈체계를 설정을 위해 한국, 미국, 중국, 일본의 성인
여성의 신체치수와 지수치를 비교 분석하였다. 신체치수 비 교한 결과(Table 5), 가슴둘레, 젖가슴둘레 크기는 미국, 중 국, 한국, 일본 순으로, 젖가슴아래둘레의 크기는 중국, 미국, 한국, 일본 순으로, 목밑둘레는 일본 한국, 중국, 미국 순으 로 나타났다.

젖가슴둘레와 젖가슴아래둘레에 대한 상대적 크기를 나 타내는 지수치 분석 결과(Table 6), 젖가슴둘레에 대한 허 리둘레 (C5/C3)는 한국 0.86 , 중국 0.82 , 미국 0.80 , 일본 0.79 순으로 나타났으며, 젖가슴둘레에 대한 엉덩이둘레 (C6/C3)는 일본, 한국, 중국, 미국 순으로 나타났고, 젖가슴 둘레에 대한 목밑둘레 $(\mathrm{C} 1 / \mathrm{C} 3)$ 는 일본 0.47 , 한국 0.45 , 중 국 0.43 , 미국 0.38 로 이는 젖가슴둘레에 비해 목밑둘레가 미국이 가장 짧았으며, 그 다음으로는 일본, 한국, 중국 순이 었다. 젖가슴둘레에 대한 겨드랑앞벽사이길이 (L1/C3)는 측 정치가 없는 미국을 제외하고, 한국, 중국, 일본 모두 같았으 며, 젖가슴둘레에 대한 겨드랑뒤벽사이길이(L2/C3) 젖가슴 둘레는 측정치가 없는 일본을 제외하고, 한국, 미국, 중국 모 두 비슷하여 젖가슴둘레에 대한 앞품과 뒤품의 크기는 거의 비슷했다. 젖가슴아래둘레에 대한 허리둘레(C5/C4)는 한국 0.99 , 미국 0.94 , 중국 0.93 , 일본 0.91 로 나타나 한국이 가장 허리둘레와 젖가슴아래둘레의 차가 가장 적었고, 젖가 슴아래둘레에 대한 엉덩이둘레 $(\mathrm{C} 6 / \mathrm{C} 4)$ 는 한국 1.23 , 미국 1.22 , 중국 1.20 , 일본 1.26 으로 나타나 일본이 젖가슴아래 둘레에 비해 엉덩이둘레가 다른 나라에 비해 상대적으로 컸 다. 젖가슴아래둘레에 대한 목밑둘레 $(\mathrm{C} 1 / \mathrm{C} 4)$ 는 일본 0.54 , 한국 0.51 , 중국 0.49 , 미국 0.45 로 미국이 몸통에 비해 가 는 목을 가졌으며, 젖가슴아래둘레에 대한 앞품과 뒤품은 네 나라가 거의 비슷한 수준을 보였다. 드롭에서는 젖가슴둘 레-허리둘레(C3-C5)는 미국이 181로 가장 크고, 한국이 121 로 가장 작았고, 엉덩이둘레-허리둘레의 하드롭(C6C5)은 일본이 252 로 가장 크고, 한국이 180 로 가장 작게 측정되었으며, 엉덩이둘레-젖가슴둘레 (C6-C3)의 드롭은 일본이 79 로 가장 크고, 미국이 30으로 가장 작게 나타나 
Table 5. Body size comparison of women of Korea, USA, China and Japan(mm)

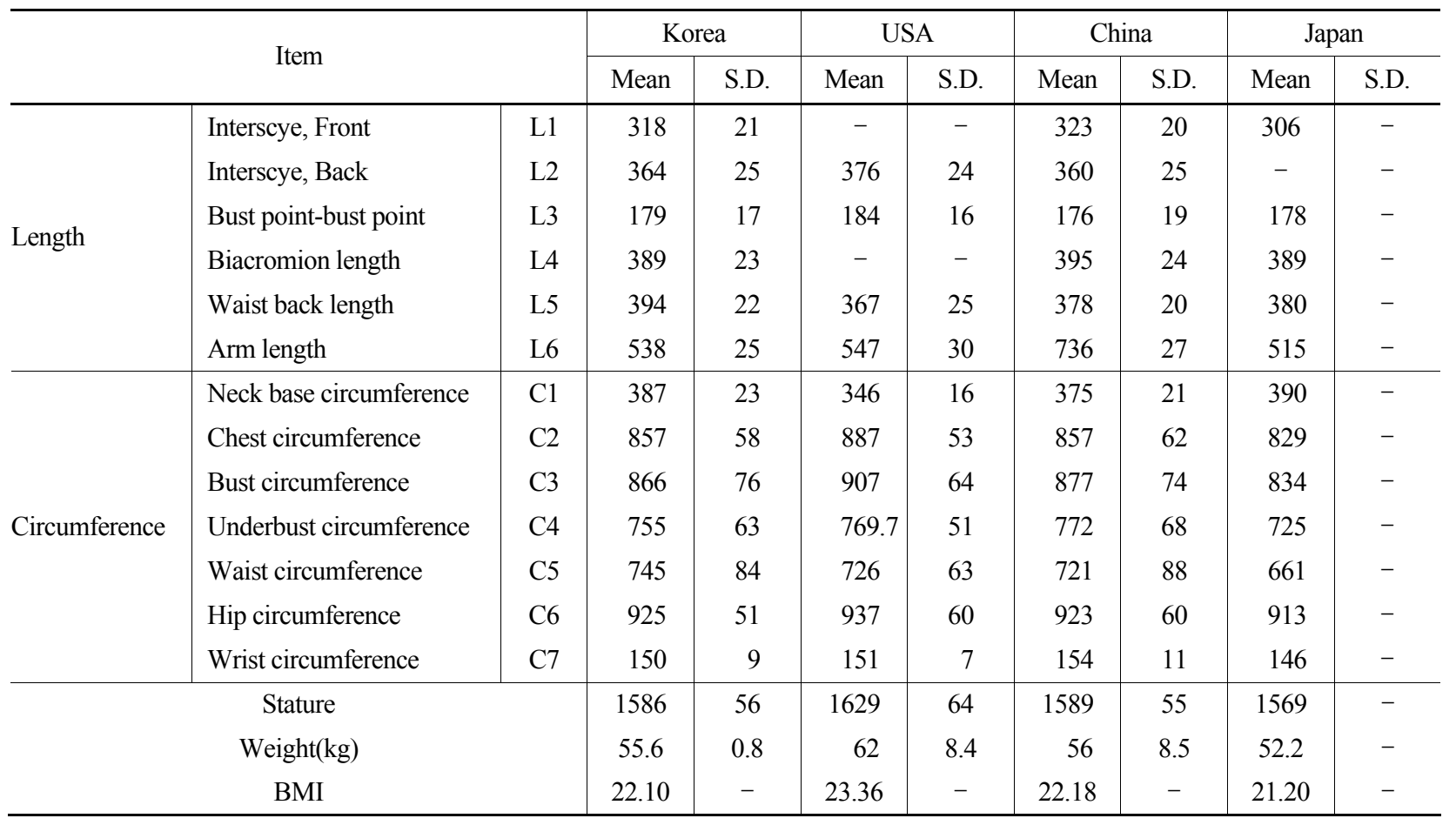

Table 6. Body index comparison of women of Korea, USA, China and Japan

\begin{tabular}{c|c|c|c|c}
\hline & Korea & USA & China & Japan \\
\hline C3-C5 & 121 & 181 & 156 & 173 \\
\hline C6-C5 & 180 & 211 & 202 & 252 \\
\hline C6-C3 & 59 & 30 & 46 & 79 \\
\hline C3-C4 & 111 & 137.3 & 105 & 109 \\
\hline C5/C3 & 0.86 & 0.80 & 0.82 & 0.79 \\
\hline C6/C3 & 1.07 & 1.03 & 1.05 & 1.09 \\
\hline C1/C3 & 0.45 & 0.38 & 0.43 & 0.47 \\
\hline C7/C3 & 0.17 & 0.17 & 0.18 & 0.18 \\
\hline L1/C3 & 0.37 & - & 0.37 & 0.37 \\
\hline L2/C3 & 0.42 & 0.41 & 0.41 & - \\
\hline C5/C4 & 0.99 & 0.94 & 0.93 & 0.91 \\
\hline C6/C4 & 1.23 & 1.22 & 1.20 & 1.26 \\
\hline C1/C4 & 0.51 & 0.45 & 0.49 & 0.54 \\
\hline C7/C4 & 0.20 & 0.20 & 0.20 & 0.20 \\
\hline L1/C4 & 0.42 & - & 0.42 & 0.42 \\
\hline L2/C4 & 0.48 & 0.49 & 0.47 & 0.00 \\
\hline
\end{tabular}

일본여성이 4 개국 중에서 가장 $\mathrm{A}$ 체형의 특징을 보여주었다. 한국과 중국 여성 또한 미국 여성에 비해 젖가슴둘레에 비
해 엉덩이둘레가 컸으며, 본 연구에서 다루는 젖가슴둘레젖가슴아래둘레 (C3-C4)는 미국이 137.3으로 가장 크고, 한국이 111 , 일본이 109 , 중국이 105 로 측정값이 다양하게 나타나 패턴 제도와 사이즈체계 설정하는데 있어서 젖가슴 아래둘레의 반영이 매우 필요하다고 사료된다.

\subsection{Construction of sizing system}

한국, 미국, 중국, 일본의 성인 여성 사이즈체계의 치수범 위와 치수간격은(Table 7) 과 같다. 한국의 사이즈체계는 치 수범위가 다른 나라에 비해 좁으므로 다른 나라의 사이즈 적 용이 쉽지는 않아 사이즈체계를 다시 검토해야 할 필요도 있 다. 또한 중국의 사이즈체계는 키-젖가슴둘레-허리둘레의 치수체계를 가지고 있어 다른 미국, 한국, 일본의 키-젖가슴 둘레-엉덩이둘레의 치수체계와 다르기 때문에 젖가슴둘레 - 키에서는 중국은 제외하여 분석하였다. 한국, 일본, 미국 세 나라는 젖가슴둘레가 증가함에 따라 엉덩이둘레가 비례 하면서 증가하는데(Figure 1), 한국, 미국, 일본이 교차하는 사이즈는 85 91과 85 94이며, 2개국이 교차하는 사이즈는 79 88, 79 91, 82 88, 82 91, 88 94, 88 97이다. 젖가 슴둘레 94 103, 엉덩이둘레 97 103까지는 일본과 미국의 사이즈범위이다.

젖가슴둘레와 키의 사이즈분포(Figure 2)는 한국이 가장 
Table 7. Women cloth sizing system of Korea, USA, China and Japan

\begin{tabular}{c|c|c|c|c|c}
\hline \multicolumn{2}{c|}{ Standard } & $\begin{array}{c}\text { Korea } \\
\text { (KS 0050) }\end{array}$ & $\begin{array}{c}\text { USA } \\
\text { (ASTM D 585-95) }\end{array}$ & $\begin{array}{c}\text { China } \\
\text { (GB/T 1335.2) }\end{array}$ & $\begin{array}{c}\text { Japen } \\
\text { (JS L 4005) }\end{array}$ \\
\hline \multirow{2}{*}{$\begin{array}{c}\text { Chest } \\
\text { circumference }\end{array}$} & Interval & 3 & 2.54 & 4 & $3(4 \mathrm{~cm}$, more than 92cm ) \\
\cline { 2 - 6 } & Range & $73 \sim 103$ & $81.3 \sim 113$ & $68 \sim 108$ & $74 \sim 124$ \\
\hline \multirow{2}{*}{$\begin{array}{c}\text { Waist } \\
\text { circumference }\end{array}$} & Interval & 3 & 2.54 & 4 & $3(4 \mathrm{~cm}$, more than 76cm) \\
\cline { 2 - 6 } $\begin{array}{c}\text { Hip } \\
\text { circumference }\end{array}$ & Range & $61 \sim 94$ & $61.0 \sim 92$ & 4 and 2 & $58 \sim 92$ \\
\cline { 2 - 6 } & Interval & - & 2.54 & $77.4 \sim 112$ & 2 \\
\hline \multirow{2}{*}{ Stature } & Interval & 5 & $86.4 \sim 119$ & 5 & $81 \sim 117$ \\
\cline { 2 - 6 } & Range & $150 \sim 170$ & $161.3 \sim 172.7$ & $81 \sim 117$ & 8 \\
\hline
\end{tabular}

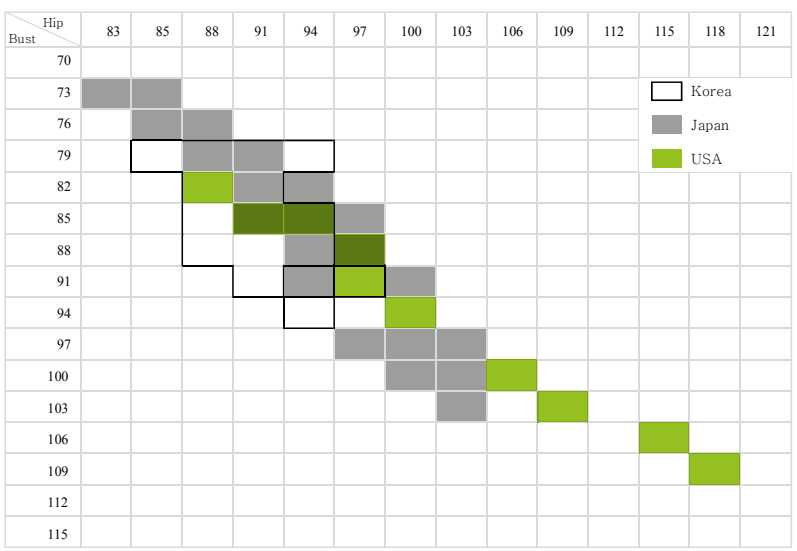

Figure 1. Body indexes(bust, hip) comparison of women of Korea, USA and Japan

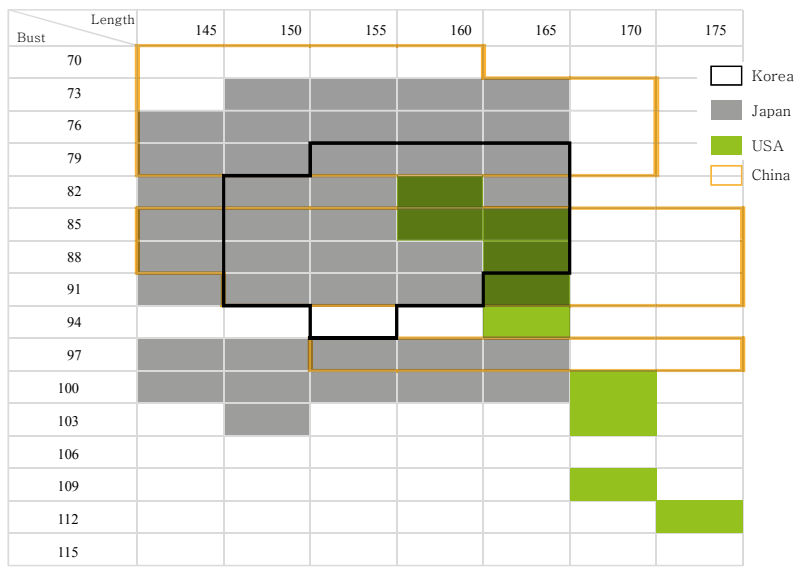

Figure 2. Body indexes(bust, lenth) comparison of women of Korea, USA, China and Japan

좁고, 중국이 가장 넓으며, 미국은 키가 $160 \mathrm{~cm}$ 이상부터 사
이즈가 형성되어 있다. 네 나라가 모두 사용하는 사이즈는 85 160, 85 165, 88 165이며, 세 나라가 모두 사용하 는 사이즈는 79 155 165, 85 150, 85 155, 88 150, 88 155, 88 160, 91 150, 91 155, 91 160, 91 165 등이다.

앞서 젖가슴둘레와 젖가슴아래둘레의 드롭에 대해 설명 한 바 있다. 젖가슴둘레와 젖가슴아래둘레의 차가 미국이 137.3 , 한국이 111 , 일본이 109 , 중국이 105 로 서양 여성 이 젖가슴둘레와 젖가슴아래둘레의 차가 동양 여성에 비해 크기 때문에 서양 여성을 기준으로 만든 옷은 동양 여성에게 맞음새에 문제가 생긴다고 설명하였다. 따라서 젖가슴둘레 외에 젖가슴아래둘레를 반영할 수 있는 사이즈체계가 필요 하다. 사이즈체계가 서로 겹쳐지는 치수를 이용하여 사이즈 체계를 설정하였다(Table 8). 미국의 성인 여성의 젖가슴둘 레와 젖가슴아래둘레의 차가 13.73 이고, 사이즈체계는 젖가 슴둘레가 82 부터 시작되며, 한국, 중국, 일본의 치수체계에 서 가장 낮은 젖가슴둘레와 미국과 중국이 마지막으로 교차 되는 젖가슴둘레 103 까지 설정하여 치수체계를 설정하였다. 따라서 젖가슴둘레와 젖가슴아래둘레의 차가 $12.5 \mathrm{~cm}$ 를 기 준으로 미만은 '가슴A-엉덩이-키'로 설정하고, 이상은 '가 슴 $\mathrm{B}-$ 엉덩이-키'로 설정하여 젖가슴이 큰 서양과 서양보다 다소 작은 동양 여성의 맞음새를 고려해, 일반적으로는 동양 여성 혹은 가슴이 $\mathrm{B}$ 컵 이하를 $\mathrm{A}$ 로, 서양 여성 혹은 가슴이 $\mathrm{B}$ 컵 이상을 $\mathrm{B}$ 로 쉽게 구분하였다.

\section{Conclusion}

본 연구는 제주도의 헬스케어시티 개장을 앞둔 시점에서 방문 및 의료관광을 위해 입국하는 관광객의 주요국가인 미 국, 중국, 일본, 한국의 치수규격을 참고로 하여 휴양복 제작 
Table 8. Construction of sizing system

\begin{tabular}{|c|c|c|c|}
\hline Name & $\begin{array}{c}\text { Bust } \\
\text { circumference }\end{array}$ & $\begin{array}{c}\text { Hip } \\
\text { circumference }\end{array}$ & Stature \\
\hline $76 \mathrm{~A}-85-150$ & $76 \mathrm{~A}$ & 85 & 150 \\
\hline $79 \mathrm{~A}-88-150$ & $79 \mathrm{~A}$ & 88 & 150 \\
\hline 79A-91-155 & $79 \mathrm{~A}$ & 91 & 155 \\
\hline 79A-91-160 & $79 \mathrm{~A}$ & 91 & 160 \\
\hline $82 \mathrm{~A}-88-155$ & $82 \mathrm{~A}$ & 88 & 155 \\
\hline $82 \mathrm{~A}-91-160$ & $82 \mathrm{~A}$ & 91 & 160 \\
\hline $82 \mathrm{~B}-88-160$ & $82 \mathrm{~B}$ & 88 & 160 \\
\hline 82B-91-160 & $82 \mathrm{~B}$ & 91 & 160 \\
\hline $85 \mathrm{~A}-91-160$ & $85 \mathrm{~A}$ & 91 & 160 \\
\hline $85 \mathrm{~A}-91-165$ & $85 \mathrm{~A}$ & 91 & 165 \\
\hline $85 A-94-160$ & $85 \mathrm{~A}$ & 94 & 160 \\
\hline $85 \mathrm{~A}-94-165$ & $85 \mathrm{~A}$ & 94 & 165 \\
\hline $85 B-91-160$ & $85 \mathrm{~B}$ & 91 & 160 \\
\hline 85B-91-165 & $85 \mathrm{~B}$ & 91 & 165 \\
\hline 85B-94-160 & $85 \mathrm{~B}$ & 94 & 160 \\
\hline 85B-94-165 & $85 \mathrm{~B}$ & 94 & 165 \\
\hline $88 \mathrm{~A}-94-160$ & $88 \mathrm{~A}$ & 94 & 160 \\
\hline $88 \mathrm{~A}-94-165$ & $88 \mathrm{~A}$ & 94 & 165 \\
\hline $88 \mathrm{~B}-97-160$ & $88 \mathrm{~B}$ & 97 & 160 \\
\hline 88B-97-165 & $88 \mathrm{~B}$ & 97 & 165 \\
\hline 91A-94-160 & $91 \mathrm{~A}$ & 94 & 160 \\
\hline 91A-94-165 & $91 \mathrm{~A}$ & 94 & 165 \\
\hline 91B-97-165 & $91 \mathrm{~B}$ & 97 & 165 \\
\hline 94B-100-165 & $94 \mathrm{~B}$ & 100 & 165 \\
\hline $97 \mathrm{~A}-100-160$ & $97 \mathrm{~A}$ & 100 & 160 \\
\hline 97A-100-165 & $97 \mathrm{~A}$ & 100 & 165 \\
\hline 97B-103-165 & $97 \mathrm{~B}$ & 103 & 165 \\
\hline $100 \mathrm{~A}-103-165$ & $100 \mathrm{~A}$ & 103 & 165 \\
\hline 100B-106-170 & 100B & 106 & 170 \\
\hline $103 \mathrm{~A}-103-170$ & $103 \mathrm{~A}$ & 103 & 170 \\
\hline 103B-109-170 & 103B & 109 & 170 \\
\hline
\end{tabular}

A: Bust Circumference-underbust circumference under $12.5 \mathrm{~cm}$

B: Bust Circumference-underbust circumference more than $12.5 \mathrm{~cm}$

에 필요한 사이즈체계를 구축하기 위한 기초연구로, 이를 위 해 2004년과 2010년의 한국 여성의 신체치수의 변화와 한 국 $\mathrm{KS}(\mathrm{KS} \mathrm{0050)}$, 미국 ASTM(ASTM D 5585-95), 중 국 $\mathrm{GB}(\mathrm{GB} / \mathrm{T} 1335.2)$, 일본 JIS(JIS L 4005)의 성인 여 성의 치수치계 분석을 통해, 젖가슴둘레와 젖가슴아래둘레를 고려한 치수체계를 구축하였다. 젖가슴둘레와 젖가슴아래둘 레의 차가 $12.5 \mathrm{~cm}$ 를 기준으로 미만은 '가슴 $\mathrm{A}-$ 엉덩이-키'
로 설정하고, 이상은 '가슴B-엉덩이-키'로 설정하였다. 이처 럼 젖가슴둘레와 젖가슴아래둘레의 차이에 의한 치수체계가 필요한 이유는 각 나라별, 혹은 연령에 따라 몸통에 비해 가 슴의 크기가 다르기 때문이다. 따라서 젖가슴둘레만으로 이 용한 패턴을 통해 얻어진 옷은 사람마다 맞음새가 다를 수 가 있다. 특히 젖가슴이 다른 부위에 비해 발달된 사람이거 나, 혹은 젖가슴이 다른 부위에 비해 덜 발달된 사람의 경우, 전체적인 여유분이나, 옆선이나 다트 등의 위치의 불균형하 게 나타날 수 있으므로 가슴과 몸통의 크기를 고려한 치수체 계는 필요하다.

연구에 사용된 자료 분석은 한국의 경우 연령 별로 분석이 가능하였으나, 미국, 일본, 중국의 경우 연령별 분석이 이루 어지지 않아서 연령별 신체치수를 파악할 필요가 있다. 따라 서, 제시된 치수체계는 한국, 미국, 일본, 중국의 모든 성인 여성의 전체 평균치를 사용했으므로 특정 연령대의 신체치 수를 반영하는 데는 한계가 있다. 그리고, 많은 빈도를 차지 하는 가슴치수 외에 제시되어 있는 치수에 대한 실험과 분 석이 필요할 것으로 사료된다. 본 연구 결과를 토대로 다음 의 연구에서는 젖가슴둘레와 젖가슴아래둘레에 대한 다른 치수항목의 평균 차이가 있는지 통계 분석을 거쳐 치수간의 관계를 파악해야 하며, 보다 세부적으로 국내 성인 여성의 자료로 사이즈체계와 빈도 분석과 제시한 치수체계를 이용 하여 의복을 설계하고 이에 따른 평가가 이루어져야 할 것 이다.

\section{Acknowledgements}

This work was supported by the research grant of the Jeju National University in 2010.

\section{References}

Byun, J. H., Research on Demand and Supply Factors of Korean Medical Tourism Industry, A Master's thesis of Yonsei Uni., 2009.

Ed Fuentes. "How to profit from medical tourism?". Money Week, 04 February. 2005.

Han, S. Y., et al. Clinical Research in the effect of Natural Dyeing using Mugwort in patients with Atopic dermatitis, The Korean Dermatological Association, 46(2s), (pp. 144-145), 2008.

Ko, S. D., The Promoting Strategy of Service Industries and Medical Tourism of Jeju, Jeju development forum, 26, summer, (pp. 27-33), 2008. 
Lee, E. J., Yoo, E. S. and Hong, J. Y., Dermal functions of cotton fabrics dyed with extract of unripe Citrus Grandis Osbeck, Proceedings of the $86^{\text {th }}$ International Conference on Textile Science, Hong Kong, 2008.

Lee, J. S., Seok, H. J. and Im, S., A Comparison Study on the Body Types of Korean Women and Korean Women Residing in Japan -Focusing on Women in Their Forties-. Journal of the Korean Society of Clothing and Textiles, 33(4), (pp. 554-562), 2009.

Lee, S. L., Pattern Story of Lee Seung Ryul. Technology and Emotion1 2nd, 2004

Lim, S. J., Dreaming of Medical Tourism Hub of Northeast Asis, Jeju Journal, (pp. 364-370), 2006.

Shim, B. J. and Kwon, Y. J., Analysis of Current Size Establishment of Clothing Sizes in China. The Journal of the Korean society of costumes, 53(1), (pp. 117-128), 2003.

Shim, B. J., A Study on the Sizes of Ready-made Clothes to Export to China - Corresponding Sizes of China Women's and Men's Readymade Clothes Sizes Based on KS size specification-, Journal of fashion business, 11(4), (pp. 152-172), 2007.

Sung, M. J., The Studies of Body Fat and Physical Characteristics between Korean and Chinese Females, Journal of the Korean Society of Clothing Industry, 8(6), (pp. 697-701), 2006.

Wee, H. J. and Sohn, H. S., A Study on Development of Apparel Sizing System for Chinese Adult Female 1 -focused on the entire group-. Journal of fashion business, 10(5), (pp. 135-158), 2006.

\section{Author listings}

Sookhee Kwon: sookhee@jeju.ac.kr

Highest degree: $\mathrm{PhD}$, Department of Clothing \& Textiles, Yonsei university

Position title: Professor, Department of Clothing and Textiles, the University of Yonsei

Areas of interest: Human Factors in Nuclear Power Plant, Risk Management

Jiun Hong: texhong@naver.com

Highest degree: M.S., Department of Clothing and Textiles, the national university of Jeju

Position title: Doctor Course, Department of Clothing and Textiles, the National University of Jeju

Areas of interest: Human Factors in Nuclear Power Plant, Risk Management

Date Received : 2012-05-14

Date Revised :2012-11-30

Date Accepted : 2012-12-02 